\title{
INFLUENCE OF ENVIRONMENTAL REGULATION ON THE GROWTH OF TOTAL FACTOR PRODUCTIVITY - AN EMPIRICAL RESEARCH BASED ON CHINA'S PROVINCIAL PANEL DATA
}

\author{
WANG, Y. ${ }^{*}-\mathrm{HAO}$, C. - ZHANG, Z. \\ School of Economics and Management, Xi'an University of Technology, Xi'an, PR China \\ *Corresponding author \\ e-mail:wangyan@xaut.edu.cn \\ (Received $8^{\text {th }}$ Mar 2019; accepted 21 $1^{\text {st }}$ May 2019)
}

\begin{abstract}
Previous researches tended to ignore the influence of environmental regulation on technical efficiency, and in this sense, the total factor productivity is easy to be overestimated. This paper establishes the translog stochastic frontier production function model, includes environmental regulation into technical inefficiency equation, calculates the total factor productivity and its composition in China (including eastern, central and western regions) from 1995 to 2015, and also makes an analytical comparison with the value not considering environmental regulation. The results show that: (1) the investment on industrial pollution control and $\mathrm{SO}_{2}$ emission intensity will significantly promote technology inefficiency, thus exerting a negative impact on economic growth; (2) environmental regulation slows down the growth rate of total factor productivity in China and all of its regions; (3) Considering the environmental regulation, technical efficiency is improved significantly and becomes the major drive behind the grow of total factor productivity, while technological progress, scale efficiency and the allocation efficiency show setback; (4) In terms of different regions, the growth rate of total factor productivity is the fastest in the east of China, and the slowest in the central region. Drives behind the growth of total factor productivity in each region are distinct.
\end{abstract}

Keywords: technical efficiency; economic growth; driving force; environmental factor; computing method

\section{Introduction}

The report of the 19th National Congress pointed out that "China's economy has been transitioning from a phase of rapid growth to a stage of high-quality development," so the country should shift from the extensive growth, which focuses on speed and scale, to intensive growth, which emphasizes efficiency. In the new stage, economic growth should not be judged merely by speed, and the quality should be regarded as the key. Over the past 30 years, due to the limitation of productivity, China's economic growth has been based on "high investment, high consumption and high emissions", which although promoted a high speed of economic development, has brought serious environmental pollution at the same time. Global Environmental Performance Index (EPI) ranked China the 109th in 180 participating countries and regions in 2016, which reflects that China's environmental situation is apparently not optimistic. Because of this, the century government has attached great importance to energy conservation and pollution emission, pointing out in "The Thirteenth Five-Year Plan" the target of "greatly improving the efficiency of exploiting energy resources, effectively controlling energy consumption, the total amount of carbon emissions, and greatly reducing major pollution emissions". The realization of this goal cannot be separated from enacting and implementing environmental regulation, the constant 
strengthening of which constitutes an inevitable trend of China's economic and social development (Barla and Perelman, 2005; Thanh and Do, 2018).

Total factor productivity, as a critical basis for measuring the quality of economic growth, has attracted wide attention from scholars. Finding a way to improve the contribution of the total factor productivity to economic growth has become a top priority for China's high-quality growth (Cai and Zhou, 2017; Sufiyan et al., 2018). Is it possible to achieve a win-win situation between environmental pollution control and economic growth? Chen (2017) and Abija and Nwankwoala (2018) found that the current establishment and enforcement of environmental regulation in China had a certain inhibitory effect on economic growth for it continuously expands the social welfare cost. It has become an urgent and significant problem in China to formulate a rational environmental regulation to promote total factor productivity. Based on this, this paper discusses the influence of environmental regulation of the growth of total factor productivity through a theoretical perspective.

\section{Literature review}

In terms of the influence of environmental regulation on total factor productivity, there are three representative views abroad: first, environmental regulation will have a negative impact on total factor productivity. Granderson and Prior (2013) and Anan (2019) analyzed and tested the influence of environmental regulation on the efficiency of the fossil fuel generation industry in the United States and its total factor productivity, and they pointed out that the increased regulatory intensity of sulfur dioxide emissions resulted in a significant growth in the costs of generating electricity, thus limiting the increase of total factor productivity in the power sector. Research conducted by Aklin (2016) demonstrated that environmental regulation would push production costs of enterprises upward, and that relatively intensified environmental regulation might lead to wrong strategic development decisions for enterprises and deviation from their original development track. This would inhibit technological progress and promotion of productivity. The empirical test results of Zárate-Marco and Vallés-Giménez also proved the above ideas, which they referred to as "following the costs theory" Second (Zárate-Marco and Vallés-Giménez, 2015), environmental regulation will promote the improvement of total factor productivity. Scholars including Klemetsen et al. (2016; Xu, 2018) and Cherkashin et al. (2015) stated that the total factor productivity under the influence of environmental regulation was higher than traditional total factor productivity, and they explained this conclusion by the Potter Hypothesis, arguing that the purpose of moderate environmental regulation was to reduce the negative impact of the environment, which could stimulate the "innovation compensation" effect, promote technological innovation, and make up costs generated by or even beyond the environmental regulation, Guo et al. (2015) conducted sample studies in refineries of Los Angeles from 1990 to 2009, finding that despite the high costs of environmental regulation in the region, the total factor productivity witnessed significant improvement. Brolund and Lundmark (2017) and Gautam et al. (2019), with the aim of exploring whether environmental laws and regulations affected the productivity and technological changes of European paper industry, conducted empirical studies by taking the total factor productivities of the paper industry in eight European countries from 1993 to 2009 as dependent variables, and the intensity of environmental regulation of various pollutants as independent variables. Results showed 
that the management of nitrogen oxides was related with the improvement of total factor productivity in the following period. Third, the influence of environmental regulation on total factor productivity is uncertain. This view holder believed that various factors such as production scale, industrial characteristics, environmental regulation policy and tools selection made the direction and degree of the influence uncertain (Naso et al., 2017; Zulkapli et al., 2018). Qu (2015) employed the data of Quebec manufacturing sector from 1996 to 2008, and they found that the environmental regulation was negatively related to total factor productivity in the same period, but when the model took lagged variables into consideration, the Potter Hypothesis took effect and they became positively related. Ravetti et al. (2016) believed that no evidence showed that environmental regulation policy had an obvious and continuous effect on innovation, and they found through further empirical tests that environmental regulation had little effect on green technology innovation of enterprises.

Domestic researches on the relationship between environmental regulation and total factor productivity started relatively late, and focused mainly on the influence of environmental regulation on technological progress and technical efficiency. Wang and Sheng (2015), starting from the internal relationship between environmental pollution and China's industrial growth, constructed the total factor productivity limited by environmental regulation, and decomposed it into technological progress and technical efficiency by Malmquist-Luenberger (ML) index method. They found that there was a positive relationship between environmental regulation and technological progress. Liu et al. (2016) and Baharuddin and Samsudin (2018) employed the slack based measure (SBM) directional distance function and the ML index to investigate factors affecting Global Trade Finance Program (GTFP) in China's 29 provinces (cities), and results displayed that appropriate market environment regulations could improve productivity via stimulating technological innovation. Li et al. (2017), with the panel data of China's 30 provinces (cities) from 2005 to 2014, conducted empirical tests on the effect of environmental tax on enterprises' technological progress. Tests results showed that the influence of environmental tax intensity on technological progress was notably positive. $\mathrm{Lv}$ et al. (2017) calculated the green total factor productivity of 28 sub-sectors of China's manufacturing industry using data envelopment analysis (DEA)-Malmquist index method, which further verified the relationship between environmental regulation and the green total factor productivity of manufacturing industry. They found that technological progress constituted the core drive for the improvement of the manufacturing industry, and that environmental technology efficiency was generally lower.

The above literature demonstrates that scholars have made fruitful achievements in the study of the relationship between environmental regulation and total factor productivity, but there still exist several problems: first, despite the fact that the DEA method has been used to incorporate environmental factors into the productivity analysis framework to calculate the total factor productivity, potential effects caused by random error are not considered. Second, the study of environmental regulation and total factor productivity is mainly limited to the relationship between environmental regulation and technological progress or technical efficiency. The relationship between environmental regulation and specific components of all factor productivity is not included. Third, the majority of the previous researches start from the micro and macro perspective of environmental regulation and total factor productivity, with little focus on regional studies. In view of the above situation, this paper under the random frontier 
framework intends to incorporate environmental regulation into technical inefficiency, constructs the economic growth accounting equation with the total amount of energy consumption, capital and labor force as production factors, and calculates the value of total factor productivity and its decomposition part, the result of which will be contrasted with the one made without considering environmental regulation. This way, the internal structure and the drive behind the influence of environmental regulation on total factor productivity growth will be explored. In addition, given that the significant difference of resource distribution, industrial structure and development stage in distinct regions of China, which makes it different the influence of environmental regulation on total factor productivity, this paper divides China into eastern, central and western regions $^{1}$ so as to measure the difference of the total factor productivities growth between diverse regions, thus providing theoretical basis for the coordinated growth of total factor productivity in various regions.

\section{Materials and methods}

\section{Stochastic frontier model}

Existed literatures adopted two methods to build the production frontier, that is, the non-parametric Data Envelopment Analysis (DEA) and the parameter stochastic frontier analysis (SFA). This paper intends to use SFA to calculate the total factor productivity, which has the following advantages over DEA: first, the error structure of SFA constitutes a composite form, which takes into consideration the influence of both technical inefficiency and random factors on efficiency, while the production frontier constructed by DEA is non-random, which attributes all deviations to technical inefficiency, and this may not coincide with the reality; second, SFA can measure efficiency and analyze the factors that affect it at the same time, while DEA must adopt the two steps; third, SFA, with statistical properties, is capable of conducting statistical tests of parameters and models, which DEA fails to achieve; Four, the SFA measures the absolute efficiency, which is convenient for comparison and analysis of different units. In contrast, DEA calculates relative efficiency, which is 1 for all units, making it difficult to compare and analyze these effective units. Therefore, this paper adopts the stochastic frontier model, and the basic form of the empirical model is as follows (Eq. 1):

$$
Y_{i t}=f\left[x_{i t}, \beta\right] \exp \left(v_{i t}-u_{i t}\right)
$$

In the above formula, i represents the province, $\mathrm{t}$ indicates time, $\mathrm{Y}$ means output, $\mathrm{f}\left(x_{i \mathrm{t}}, \beta\right)$ indicates production frontier, $x$ represents input factor, and $\beta$ is the parameter to be estimated. ( $\left.v_{\text {it }}-u_{\text {it }}\right)$ is a composite error structure, in which $v_{\text {it }}$ represents random disturbance variable, $u_{i t}$ indicates the technical inefficiency of production and they are independent of each other.

\footnotetext{
${ }^{1}$ The eastern, central and western regions in China in this paper are divided as follows: the eastern region includes Beijing, Tianjin, Hebei, Liaoning, Shanghai, Jiangsu, Zhejiang, Fujian, Shandong, Guangdong, Hainan and Guangxi. The central region includes Shanxi, Inner Mongolia, Jilin, Heilongjiang, Anhui, Jiangxi, Henan, Hubei and Hunan. The western region includes Chongqing, Sichuan, Guizhou, Yunnan, Shaanxi, Gansu, Qinghai, Ningxia and Xinjiang.
} 
In actual production activities, although the related factors of environmental regulation cannot be directly included in the production equation, it may exert influence on the total factor productivity by affecting the technical inefficiency. Neglecting these factors will result in the inaccuracy of estimated results. In this sense, the following technical inefficiency regression equation is established as follows (Eq. 2):

$$
u_{i t}=\delta_{0}+\delta_{i} Z_{i t}
$$

$\delta_{0}$ is a constant term, $Z_{i t}$ indicates the factor affecting technical inefficiency, $\delta_{i}$ represents estimated coefficient of the factor, which, when positive, indicates that the factor restrain the promotion of technical efficiency, and vice versa.

\section{Selection of production function and decomposition of total factor productivity}

Early classical economists regard labor and capital as the main factors affecting economic output, and natural resources are often considered to be able to replace each other or be substituted by other productive factors. This is not consistent with the actual situation in which a large number of non-renewable resources are required in the process of production. In 2016, China surpassed the United States in the consumption of renewable energy, ranking the first in the world, and the total energy consumption in China accounted for $23 \%$ that of the world. Massive energy consumption has brought serious environmental pollution and climate change (Xiao et al., 2017; Kumar and Kumar, 2018). Therefore, research regarding economic growth in China cannot overlook the input of energy elements in the production process. This paper intends to employ capital (K), labor force (L) and energy (E) to jointly construct the production function $\mathrm{Y}=\mathrm{f}(\mathrm{K}, \mathrm{L}, \mathrm{E})$.

Compared with the Cobb Douglas production function (C-D), the translog production function is inclusive and easier to estimate, which can better avoid the deviation caused by misspecification of production functions (Wang and Qi, 2017; Onwuka et al., 2019). In addition, considering the substitution effect between input factors, whether the technological progress is neutral or the technological progress should all be reflected in the model, this paper selects the time-varying model of translog production function.

$$
\begin{aligned}
& \ln y_{i t}=\ln f\left[x_{i t}(t), t\right]+\left(v_{i t}-u_{i t}\right) \\
& =\beta_{0}+\beta_{l} \ln L_{i t}+\beta_{k} \ln K_{i t}+\beta_{e} \ln E_{i t}+\beta_{t} t+\beta_{k l} \ln K_{i t} \ln L_{i t}+\beta_{k e} \ln K_{i t} \ln E_{i t}+\beta_{l e} \ln L_{i t} \ln E_{i t} \\
& +\beta_{k l e} \ln K_{i t} \ln L_{i t} \ln E_{i t}+\beta_{k t} \ln K_{i t}+\beta_{l t} t \ln L_{i t}+\beta_{e t} t \ln E_{i t}+\beta_{t^{2}} t^{2}+\beta_{l^{2}} \ln ^{2} L_{i t}+\beta_{k^{2}} \ln ^{2} K_{i t} \\
& +\beta_{e^{2}} \ln ^{2} E_{i t}+v_{i t}-u_{i t}
\end{aligned}
$$

According to Solow (1957), the growth of total factor productivity was output growth deduct input growth. He believed that technological progress was the same factor as total factor productivity, and did no segmentation research on total factor productivity. Kumbhakar and Lovell (2000) further decomposed the growth of total factor productivity into four factors: technological progress $(\triangle \mathrm{TP})$, technological efficiency change $(\triangle T E)$, scale efficiency change $(\triangle S E)$ and allocation efficiency change $(\triangle \mathrm{AE})$, which provided a new way for the in-depth study of economic growth pattern. Based on this, this paper decomposes total factor productivity into the following four parts. 
(1) The rate of technological progress. It reflects the technological progress of production frontiers, representing the output with the change of time under the condition of constant input elements. Taking log of formula (Eq. 3) and taking derivatives of $\mathrm{t}$ can generate the following formula $(E q .4)$ :

$$
\Delta T P=\frac{\partial f}{\partial t}=\beta_{t}+\beta_{l t} \ln L_{i t}+\beta_{k t} \ln K_{i t}+\beta_{e t} \ln E_{i t}+2 \beta_{t^{2}} t
$$

(2) The rate of technical efficiency change. The index refers to, under the same factor input and technology level, the ratio of actual output and frontier output (maximum output) with the changes of time (Eq. 5).

$$
\Delta T E=-\frac{d u_{i t}}{d t}=\frac{T E_{i t}}{T E_{i t-1}}-1
$$

(3) The rate of scale efficiency change. Scale efficiency refers to the changes of output according to the increase of factor input with the enlargement of production scale. There are three kinds of situations, that is, the increase, decrease and unchanged scale efficiency. The formula for the rate of scale efficiency change $(E q .6)$ is shown below:

$$
\begin{gathered}
\Delta S E=(E-1) \sum_{j} \frac{E_{j}}{E} x_{j}=\left(f_{1}+f_{k}+f_{\theta}-1\right) \\
\times\left(\frac{f_{l}}{f_{l}+f_{k}+f_{k}} \times L+\frac{f_{k}}{f_{l}+f_{k}+f_{k}} \times K+\frac{f_{k}}{f_{l}+f_{k}+f_{k}} \times \dot{E}\right)
\end{gathered}
$$

According to the Equation 3:

$$
\begin{aligned}
& f_{l}=\frac{\partial f}{\partial l}=\beta_{l}+\beta_{e l} \ln E_{i t}+\beta_{l k} \ln K_{i t}+\beta_{e l k} \ln E_{i t} \ln K_{i t}+\beta_{l t} t+2 \beta_{l^{2}} \ln L_{i t} \\
& f_{k}=\frac{\partial f}{\partial k}=\beta_{k}+\beta_{e k} \ln E_{i t}+\beta_{l k} \ln L_{i t}+\beta_{e l k} \ln E_{i t} \ln L_{i t}+\beta_{k t} t+2 \beta_{k^{2}} \ln K_{i t} \\
& f_{e}=\frac{\partial f}{\partial e}=\beta_{e}+\beta_{e l} \ln L_{i t}+\beta_{e k} \ln K_{i t}+\beta_{e l k} \ln L_{i t} \ln K_{i t}+\beta_{e l} t+2 \beta_{e^{2}} \ln E_{i t}
\end{aligned}
$$

(4) The rate of allocation efficiency change. This mainly examines the contribution of factor structure changes to total factor productivity in the production process under given frontier technological level. The equation is as follows (Eq. 7):

$$
\begin{gathered}
\Delta A E=\sum_{j}\left[\left(\frac{E_{j}}{E}-s_{j}\right) \times \dot{x}_{j}\right]=\left(\frac{f_{l}}{f_{l}+f_{k}+f_{e}}-\frac{L}{L+K+E}\right) \times \dot{L} \\
+\left(\frac{f_{k}}{f_{l}+f_{k}+f_{e}}-\frac{K}{L+K+E}\right) \times \dot{K}+\left(\frac{f_{e}}{f_{l}+f_{k}+f_{e}}-\frac{E}{L+K+E}\right) \times \dot{E}
\end{gathered}
$$

The empirical study of the early stochastic frontier model is carried out in two steps. First, the maximum likelihood estimation is made to the frontier production function to obtain the coefficients of the explanatory variables. Then the regression equation is 
reconstructed by separating out the technical inefficiencies and other exogenous explanatory variables of non-factor inputs. However, there still exist the following problems: first, it is necessary to assume that there is no correlation between the exogenous factors and the input factors, the omission of these variables will result in deviation of the technical efficiency in the first step estimation. If the first step is biased, the estimation of coefficient of the technical efficiency equation in the second step will also witness deviation. Second, the stochastic frontier model often assumes that the distribution of the invalid term is the same, but in the second step technical efficiency regression equation, the technical efficiency term is changed with the different external variables, which forms a contradiction (Chen and Zhang, 2016). In contrast, one-step method can avoid these problems. Wang and Schmidt (2002) verified that one step method was superior to the two-steps method by Monte Carlo simulation. In this sense, this paper, for the purpose of attaining more accurate conclusions, employs the maximum likelihood method and one-step regression estimation method. In addition, this paper first assumes that the distribution of the technical invalid term is a truncated normal distribution, because compared with the exponential distribution and the halfnormal distribution, it is more flexible. and this hypothesis will be tested later.

\section{Variables selection and data description}

According to the constructed stochastic frontier model, this paper adopts $\mathrm{K}, \mathrm{L}$ and $\mathrm{E}$ as input variables and gross domestic product (GDP) as output variables. As for K, the capital stock, according to the estimation results of Shan (2008), through the perpetual inventory method, the data is expanded to 2015 under the assumption of $10.96 \%$ capital depreciation rate. The price level is converted to that of the year 1995 according to the corresponding Price Indices of Investment in Fixed Assets. The calculation method of the labor force (L) is the number of the employees at the end of the year in each province multiplied by the average wage of employees, which are handled according to the consumer price index in 1995 as the base period. GDP is based on the retail price index in 1995.

Variables representing environmental regulation are numerous, and in order to comprehensively investigate the impact of different types of environmental regulation on total factor productivity, this paper chooses to measure environmental regulations by environmental pollution control investment (invadd), the number of environmental regulations (fg) and the emission intensity of industrial $\mathrm{SO}_{2}$ (strs). As the most basic embodiment of the government's environmental regulation, the investment in environmental pollution control is calculated as follows: (the actual pollution control input of the year / total industrial output value) $\times 1000$. As for the variable of environmental regulations number, referring to Cole et al. (2008), the intensity of environmental regulation could be examined by the number of environmental regulations and administrative penalties related to environmental protection. The emission of industrial $\mathrm{SO}_{2}$ can reflect the enterprise's efforts to improve the environment under the government's environmental regulations (Barla and Perelman, 2005). In addition, taking into consideration other factors that may affect the total factor productivity, this paper selects the economic development level (ag) and the urbanization rate (urban) as control variables, in which the former is measured by the per capita GDP, to be specific, by GDP deflator with the year 1995 as the base period, while the latter variable is evaluated by the ratio of the urban population to the total population in each province at the end of the year (Yuan et al., 2017). 
In this paper, 30 provinces (cities) and autonomous regions (excluding Tibet) in China are used as samples, and the interval is from 1995 to 2015. The data is collected from China Statistical Yearbook, China Energy Statistical Yearbook and China Environment Yearbook (1996-2017).

\section{Discussion}

This paper employs the stata14.0 software calculate the stochastic frontier regression of the translog production function. In model 2, results were estimated by introducing environmental regulation into the technical inefficiency equation and performing a onestep regression with the production efficiency equation. Considering that the focus of this paper is to study the influence of environmental regulation on the total factor productivity, modules in the technical invalid equation without factors related to environmental regulation are also estimated (model 1), which makes it possible to further explore the difference of the total factor productivity with and without considering the environmental regulation (Xiong et al., 2017).

The estimation results (Table 1) show that the two models have achieved sound regression results, indicating that the stochastic frontier set in this paper is reasonable. In model 1 and model 2, the coefficients of capital, labor and energy factors are positive and constitute at least $10 \%$ of the significant level, which means the influence of these three factors on economic growth is positive, but the contribution of capital and labor factors is greater than that of energy factors. Compared with model 1, the regression coefficient of model 2 is more significant. In addition, the value of $\gamma$ in the two models is close to 1 , which indicates that the phenomenon of production inefficiency exists generally in all provinces in China, and that the method of analyzing the translogarithm stochastic frontier of technical invalid term to study the dynamic state of total factor productivity with environmental regulation is necessary and reliable.

Table 1. Estimation results

\begin{tabular}{|c|c|c|c|c|c|}
\hline \multicolumn{6}{|c|}{ Estimation of production efficiency equation } \\
\hline Variables & Model 1 & Model 2 & Variables & Model 1 & Model 2 \\
\hline lnk & $1.5453^{* * *}$ & $1.6980^{* * *}$ & lntl & 0.005 & -0.0004 \\
\hline $\operatorname{lnl}$ & $0.4381^{*}$ & $0.4945^{* *}$ & lnte & $-0.0252^{* * *}$ & $-0.0182^{* * *}$ \\
\hline lne & $0.0868^{*}$ & $0.1844^{*}$ & lnkle & 0.0037 & $0.0044^{*}$ \\
\hline $\mathrm{t}$ & $-0.2548^{* * *}$ & $-0.2664^{* * *}$ & $\operatorname{lnk} k^{2}$ & $-0.1646^{* * *}$ & $-0.1838^{* * * *}$ \\
\hline $\operatorname{lnkl}$ & $0.2151^{* * *}$ & $0.2074^{* * *}$ & $\operatorname{lnl} 1^{2}$ & $-0.1290^{* * *}$ & $-0.1158^{* * *}$ \\
\hline lnke & $0.0844^{* *}$ & $0.0712^{*}$ & $\ln e^{2}$ & 0.027 & $0.0410^{*}$ \\
\hline lnle & $-0.1165^{* *}$ & $-0.1269^{* * *}$ & $t^{2}$ & $-0.0032^{* * *}$ & $-0.0026^{* * * *}$ \\
\hline lntk & $0.0322^{* * *}$ & $0.0344^{* * *}$ & Constant & $-3.265^{* * *}$ & $-3.3818^{* * *}$ \\
\hline \multicolumn{6}{|c|}{ Estimation of technical invalid equation } \\
\hline Variables & Model 1 & Model 2 & Variables & Model 1 & Model 2 \\
\hline $\operatorname{lnag}$ & 2.7879 & $-0.1192^{* * * *}$ & Loglikelihood & 436.666 & 492.683 \\
\hline lnurban & $-9.9672^{* * *}$ & $-0.1511^{* * *}$ & $\gamma$ & 0.694 & 0.627 \\
\hline lninvadd & & $0.0208^{* *}$ & Constant & $-4.322^{* * *}$ & $1.010^{* * *}$ \\
\hline $\operatorname{lnfg}$ & & 0.0097 & & & \\
\hline lnstrs & & $0.0272^{*}$ & & & \\
\hline
\end{tabular}

$*$, **and $* * *$ represent, respectively, the significant level of $10 \%, 5 \%$ and $1 \%$. $\gamma$ indicates the ratio of invalid term variance to the entire stochastic error term variance, which reflects the importance of invalid term to the entire stochastic error term 
The regression coefficient of related indicators of environmental regulation is estimated by the technical inefficiency, which is the result of the industrial pollution control investment and industrial $\mathrm{SO}_{2}$ emission intensity, as an explanatory variable. From the regression results, the industrial pollution control investment is more significant in the form of technical invalidity as the $1 \%$ increase in the proportion of the investment to the industrial added-value would lead to $2.08 \%$ growth in the technical invalidity, which is not conducive to economic growth (Mut, 2018). This coincides with the "following the costs theory" of environmental regulation. The coefficient of industrial $\mathrm{SO}_{2}$ emission intensity is positive, which can be understood as the emission of pollutants in the production process out of enterprises' own interests. This indicates that in the future actions of saving energy and reducing emission, enterprises' emission of $\mathrm{SO}_{2}$ should be controlled more strictly. The coefficient of the number of environmental legislation published by local governments is 0.0097 , but the statistical test value is not significant. Moreover, the coefficients of per capita GDP and urbanization rate are notably negative, indicating that the level of regional economic development and urbanization are favorable for the improvement of technical efficiency (Hajikhani, 2017).

The conclusion of stochastic frontier analysis tends to rely on the function form of the model, and in order to ensure that the model is correct, this paper carries out a likelihood ratio test, in the broad sense, for the translog form of the production function, and the existence of technical inefficiency and technological progress, the statistic is $\lambda=-2 \ln \left[L\left(H_{0}\right) / L\left(H_{1}\right)\right]$, with $L\left(H_{0}\right), L\left(H_{1}\right)$ as the likelihood function value of the original hypothesis and the alternative hypothesis respectively. If the null hypothesis is established, the test statistic $\lambda$ obeys the Mixed Chi-square Distribution, and the degree of freedom is the number of the constrained variables. Test results are shown in Table 2.

Table 2. Test results of hypothetical model

\begin{tabular}{c|c|c|c|c}
\hline Original hypothesis & $\mathrm{L}\left(H_{0}\right)$ & $\lambda$ & $\begin{array}{c}\text { Critical } \\
\text { value }\end{array}$ & $\begin{array}{c}\text { Test } \\
\text { results }\end{array}$ \\
\hline$H_{0^{1}} \beta_{k^{2}}=\beta_{l^{2}}=\beta_{e^{2}}=\beta_{t^{2}}=\beta_{k l}=\beta_{k e}=\beta_{e l}=\beta_{k l e}=\beta_{h t}=\beta_{i t}=\beta_{e t}$ & 312.22 & 360.82 & 24.72 & Refusal \\
\hline$H_{0}: \beta_{t}=\beta_{t^{2}}=\beta_{k t}=\beta_{l t}=\beta_{e t}=0$ & 246.21 & 492.84 & 15.09 & Refusal \\
\hline$H_{0}: \gamma=\mu=\eta=0$ & 429.98 & 126.30 & 15.09 & Refusal \\
\hline$H_{0}: \beta_{k t}=\beta_{l t}=\beta_{e t}=0$ & 396.78 & 191.70 & 11.34 & Refusal \\
\hline
\end{tabular}

The unlimited $\log$ likelihood is $L\left(H_{1}\right)=492.63$, and the significance level of critical value is $1 \%$

The first original hypothesis indicates that all the interaction items and square term coefficients in the production function are zero, which means that employing the C-D production function is enough, and that no translog form is needed (Table 2); the second original hypothesis assumes that all the time dependent variables in the model are zero, that is, there exists no frontier technological progress; the third original hypothesis is designed to test the existence of the technical inefficiency. When $\gamma$ is zero, it shows that the proportion of the variance of the technical inefficiency to the variance of stochastic error term is zero, and it is completely not necessary to consider this term. If $\mu$ is zero, the technical inefficiency obeys a half-normal distribution rather than a truncated normal distribution. When $\eta$ is zero, there is no need considering the time- 
varying effect of the technical inefficiency. The last original hypothesis indicates that if the interaction coefficients of time and the three factors are all zero, the technological progress is not Hicks-neutral (Pascual-Córdova, 2018). From the test results, all the zero hypotheses are rejected, which proves that it is reasonable to use the translog form of production function, with the technical inefficiency objectively existing.

\section{Results}

According to the regression results of the stochastic frontier model (Table 3), the growth rate of total factor productivity can be estimated. At the same time, in order to understand the influence of the environmental regulation, when added the technical inefficiency, on the total factor productivity more clearly, this paper will combine the two situations of considering and not considering the environmental regulation and give an analysis of the two cases according to the regions divided above (eastern, central and western regions of China) to explore the differences between the regional total factor productivity growth (Huang et al., 2017).

When not considering the environmental regulation, although the starting points of economic development is distinct, the total factor productivity (TFP) of the eastern, central and western regions have achieved rapid growth, with the average growth rate of $5.15 \%, 3.99 \%$ and $4.19 \%$, respectively. TFP growth is the fastest in the eastern region, and the slowest in the central region. The total factor productivity of all regions decline significantly in 2006, which is related to the deterioration of the macroeconomic situation in China, such as the stock market turbulence in China, the rising price of crude oil and the hit of domestic export enterprises. In the following years, the gap of TFP growth rate in the three major regions has been gradually narrowed, and the central and western regions had a tendency to catch up with the eastern region. After the inclusion of environmental regulation factors in the technical inefficiency, the growth rate of TFP in the three regions slow down, with the average growth rate of $3.68 \%$, $2.52 \%$ and $2.76 \%$ respectively, and the central and western regions even take on a negative growth. In the majority of years, the growth rate of TFP is still the highest in the eastern region, and the central region, as the lowest in terms of the average growth rate of TFP, the largest decline also appears after the inclusion of environmental regulation (Perozo, 2016). Since China's reform and opening up, the economic development in the central region is ordinary, and its second and third industries starts late. With the promotion of "the rise of central China strategy", some manufacturing industries and heavy chemical industries of high energy consumption and pollution have achieved development first. However, due to the restrictions of capital and technology as well as relatively relaxed environmental policies, the environmental regulation was "selectively ignored", which, while promoting the economic development in the region, aggravated the problem of environmental pollution $(\mathrm{Qu}$ and $\mathrm{Xi}, 2012)$. The western region is vast and rich in resources. With the implementation of the strategy of "developing the west", its late-mover advantages gradually become noticeable, forming the trend of catching up with the developed areas. Even in the times of the macroeconomic situation deterioration in China, it still maintained the rising momentum. However, the rapid growth of the area is mainly dependent on its rich resources, and pollutant emission increased rapidly in the development process, leading to the poor TFP growth rate when considering environmental regulation. 
Table 3. TPF growth in China's regions with and without considering environmental regulation over 1995-2015 (in \%)

\begin{tabular}{c|c|c|c|c|c|c}
\hline \multirow{2}{*}{ Year } & \multicolumn{3}{|c|}{ TPF growth without environmental } & \multicolumn{3}{c}{ TPF growth with environmental } \\
& \multicolumn{3}{|c|}{ regulation } & \multicolumn{3}{c}{ regulation } \\
\cline { 2 - 6 } & East & Central & West & East & Central & West \\
\hline $1995-1996$ & 1.876 & 0.647 & 1.717 & 0.291 & 0.142 & 0.391 \\
$1996-1997$ & 2.000 & 0.482 & 0.633 & 1.077 & -1.319 & -0.725 \\
$1997-1998$ & 2.259 & -0.457 & -0.366 & 2.002 & -0.875 & -1.639 \\
$1998-1999$ & 3.826 & 0.859 & 0.581 & 2.387 & -1.935 & -1.712 \\
$1999-2000$ & 4.057 & 1.276 & 0.608 & 3.507 & -1.062 & -1.341 \\
$2000-2001$ & 4.214 & 1.679 & 1.398 & 5.163 & 2.652 & 2.431 \\
$2001-2002$ & 5.282 & 2.169 & 2.200 & 5.598 & 2.250 & 0.991 \\
$2002-2003$ & 4.733 & 2.838 & 2.915 & 3.900 & 2.845 & 2.463 \\
$2003-2004$ & 5.742 & 3.744 & 3.670 & 5.185 & 2.084 & 1.344 \\
$2004-2005$ & 5.687 & 3.726 & 4.157 & 4.090 & 3.233 & 2.817 \\
$2005-2006$ & -2.844 & -3.417 & 3.969 & -5.309 & -3.781 & 2.894 \\
$2006-2007$ & 2.208 & 5.185 & 4.704 & 3.722 & 2.809 & 3.815 \\
$2007-2008$ & 6.411 & 5.698 & 4.974 & 4.915 & 4.312 & 3.761 \\
$2008-2009$ & 6.797 & 6.106 & 5.828 & 4.937 & 4.604 & 4.424 \\
$2009-2010$ & 7.641 & 6.838 & 7.013 & 6.105 & 5.839 & 6.537 \\
$2010-2011$ & 7.333 & 7.379 & 7.018 & 3.637 & 6.545 & 5.722 \\
$2011-2012$ & 8.312 & 7.735 & 7.371 & 4.816 & 5.588 & 5.388 \\
$2012-2013$ & 8.746 & 9.037 & 7.847 & 5.021 & 3.397 & 4.530 \\
$2013-2014$ & 9.172 & 8.661 & 8.331 & 5.567 & 6.498 & 5.818 \\
$2014-2015$ & 9.498 & 9.526 & 9.201 & 6.917 & 6.478 & 7.384 \\
\hline Average & 5.147 & 3.986 & 4.188 & 3.676 & 2.515 & 2.764 \\
\hline
\end{tabular}

In order to explore the influence of environmental regulation on the decompositions of total factor productivity and regional differences after including environmental regulation in technical inefficiency, this paper further analyzes the TFP growth rate by decomposing it into four parts: technological progress $(\triangle T P)$, technical efficiency change $(\triangle T E)$, scale efficiency change $(\triangle \mathrm{SE})$ and allocation efficiency change $(\triangle \mathrm{AE})$. This is much closer to the essence of the growth of total factor productivity. It can be seen from Table 4 that when not considering the environmental regulation, the technological progress of the three regions shows a positive growth trend, and it has become the major source of the total factor productivity growth (Table 4), while the contribution of the technical efficiency change is very small or even negative, which is similar to the conclusions of produced by Wang et al. (2006), Tian et al. (2011). After considering the environmental regulation, the technical efficiency change in the three regions has been obviously improved, with the average value of the eastern region rising from $-0.02 \%$ to $1.61 \%$, and the central and western regions increasing to $2.14 \%$ and $2.08 \%$ respectively, which constitutes the main driving force of the TFP growth. In contrast, the technological progress in all regions slows down, in which technological progress growth rate in the eastern region becomes slower although it is still growing. The technological retreat in the central and western regions is more obvious, with the western region most severely affected. The average value of the technological progress 
in the western region falls from $1.5 \%$ to $-0.79 \%$, and this index shows negative growth every year from 1995 to 2008. It is not difficult to find that the eastern coastal areas is often close to the production frontier or directly on the frontiers, so a large part of the increase in productivity demonstrates the forward movement of the frontiers, that is, technological progress (Perozo, 2016). However, in the underdeveloped areas like the central and western regions, due to the lack of inner drive of technological progress, production relies on technology introduction and simple imitation, and the increase in productivity takes more of the form of the improvement in technical efficiency.

The research result also shows that the growth rate of scale efficiency demonstrates a declining trend in the western, central and eastern regions regardless of the influence of environmental regulation. However, after taking into consideration the environmental regulation, the growth rate of scale efficiency in the three regions all shows a decrease, with the average growth rate in the eastern region falling most dramatically from $1.1 \%$ to $0.45 \%$, during which period there even exist diseconomies of scale. This is related to the overdependence on the increase of production factor input in the process of economic development, which leads to the decrease of the marginal output of the production factors and the loss of the scale efficiency. The change of the scale efficiency of the central and western regions reflects a relatively strong positive effect, indicating that the two regions are in the stage of scale economy (Jamali, 2016). The growth rate of the scale efficiency in the west region is generally higher than that in the central region, indicating that western region has an obvious advantage in terms of scale efficiency, which is a main factor that makes up for the difference of growth of total factor productivity against other regions. In addition, the allocation efficiency of production factors was ignored in the documents in the past, but this paper finds out that the efficiency allocation is an objective existence after calculation, and there is a continuous and obvious fluctuation of the allocation efficiency in different regions over the past 20 years (Yu, 2019). Without taking environmental regulation into consideration, the average growth rates of allocation efficiency in eastern, central and western regions are $0.40 \%,-0.44 \%$ and $0.77 \%$. The allocation efficiency of the three regions declines if taking environmental regulation into account, and the average growth rate of western region, which is the most affected region, declines from $0.77 \%$ to $-0.17 \%$. This indicates that environmental regulation cannot optimize the allocation of resources.

In general, if taking the technical inefficiency resulted by environmental regulation into consideration, the growth of total factor productivity will slow down in most years, and the growth rate will decrease progressively in eastern, western and central regions, and the sources of the growth of total factor productivity will be different. Eastern region has more obvious advantage of technical progress, and the change rate of scale efficiency is the main reason that stops the growth of total factor productivity in this region. The total factor productivity declines in western region mainly because the range of technical efficiency improved is smaller than the falling range of technical progress and allocation efficiency. The total factor productivity in central region is the lowest, the technical efficiency was improved in the period of analysis, but the returns to scale, allocation efficiency and technical progress all declined to some extent, all these factors resulted in the decrease of the growth of TFP. Therefore, when calculating the total factor productivity, if the impact that environmental regulation exerts on productivity (technical efficiency) is ignored, the total factor productivity of our country is likely to be overestimated, and the related policy suggestions will be misleading to some extent. 
Table 4. TFP growth's decomposition in China's regions with and without considering environmental regulation over 1995-2015 (in \%)

\begin{tabular}{|c|c|c|c|c|c|c|c|c|c|c|c|c|c|c|c|c|c|c|c|c|c|c|c|c|}
\hline \multirow{3}{*}{ Year } & \multicolumn{12}{|c|}{ TFP growth's decomposition without considering environmental regulation } & \multicolumn{12}{|c|}{ TFP growth's decomposition with considering environmental regulation } \\
\hline & \multicolumn{3}{|c|}{$\triangle \mathrm{SE}$} & \multicolumn{3}{|c|}{$\triangle \mathbf{A E}$} & \multicolumn{3}{|c|}{$\triangle \mathbf{T P}$} & \multicolumn{3}{|c|}{$\triangle \mathbf{T E}$} & \multicolumn{3}{|c|}{$\triangle \mathbf{S E}$} & \multicolumn{3}{|c|}{$\triangle \mathbf{A E}$} & \multicolumn{3}{|c|}{$\triangle \mathbf{T P}$} & \multicolumn{3}{|c|}{$\triangle \mathbf{T E}$} \\
\hline & East & C & est & ast & C & & ast & C & est & st & & est & ast & C & st & East & & est & ast & & West & East & & \\
\hline & 54 & 505 & 4 & 75 & 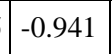 & 9 & 2.032 & 9 & 823 & 64 & 353 & 157 & 02 & 6 & 165 & 379 & 9 & 922 & .006 & & .247 & 711 & .074 & 55 \\
\hline & & & & & & & 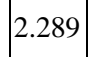 & 7 & & & & 7 & -0.030 & & 2 & 0 & -1.628 & 2 & 2 & & 2 & 5 & 3 & 2417 \\
\hline & 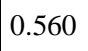 & & & & & & 2 & & & & & & & & & & & & & & & & & \\
\hline th & - & 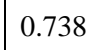 & 318 & 0.248 & .007 & -0.081 & 2.900 & 766 & .538 & 0.047 & - & .118 & -1 & 51 & 1.282 & 0.628 & .965 & -0.661 & 0.778 & -1.402 & -2.999 & 0.350 & -0.018 & 0.0 \\
\hline & & & & 0.377 & .765 & -0.121 & 3.033 & 64 & 7 & ( & 84 & 0.519 & 34 & 2 & 380 & 0.910 & 33 & 73 & 922 & & 8 & 1.620 & 9 & 0.170 \\
\hline 2 & 0.714 & 851 & 4 & ( & -0.641 & -0 & 3 & 299 & 4 & . & 171 & 1 & 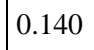 & & 2 & & 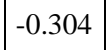 & 77 & 7 & & & & & $14 \mathrm{c}$ \\
\hline & & 政 & 338 & 1.094 & 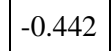 & 467 & 3.379 & . & 564 & -0.052 & 100 & 0.169 & 2 & & 1.229 & 2.003 & . & 0.051 & | & & -1.925 & & & . \\
\hline & & & & 45 & 172 & 0 & 3.546 & 1 & & 0.01 & & 025 & 2 & & 341 & & 4 & & 45 & & .653 & & 859 & 2.692 \\
\hline & & 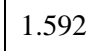 & 493 & ( & & & 3.689 & & ( & & 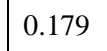 & & & & & & .202 & & & & & & & 10. \\
\hline & 839 & 896 & 72 & 137 & -0.258 & 9 & 3.919 & 2.105 & 161 & 027 & 8 & 5 & 0.643 & 6 & 514 & 0.167 & 4 & 64 & 1.902 & 6 & 1. & 38 & 5 & 103 \\
\hline & 32 & 752 & 2 & 801 & 576. & 0 & 4.14 & 56 & 446 & 5 & $\left.\right|^{-}$ & 141 & 0 & 102 & 1.787 & -8.646 & -6.750 & 0101 & 20 & 25 & -0.821 & 2.093 & 2 & 1828 \\
\hline & 556 & & 7 & -3.680 & & 5 & 4.521 & 2.954 & 80 & & -( & 402 & & & 1.684 & & -2.334 & & & & -0.509 & 2.36 & .836 & .0 \\
\hline & 469 & 100 & 793 & 0.117 & 278 & 789 & 4.890 & 3.415 & .081 & -0.065 & -0.095 & 0.312 & 0.784 & 1.403 & 1.536 & -0.975 & -1.654 & -0.278 & 2.915 & 490 & -0.141 & 2.191 & 3.073 & 2.64 \\
\hline & 666 & 257 & + & ( & 0165 & 4 & 5.3 & 3 & 0 & 7 & - & 53 & 0.892 & 1.561 & 14 & -1 & -1.6 & 0.033 & 3.344 & (1) & 0.292 & 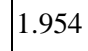 & 2.681 & 1 \\
\hline & 764 & & 355 & & & & 5.701 & & & -0.162 & & 0.221 & & & 1.950 & & & -0.104 & & & 0.727 & 2.144 & 02 & 3.70 \\
\hline 2010 & 514 & 314 & 2.430 & -0.231 & 354 & 232 & 6.067 & 4.812 & .236 & -0.117 & -0.100 & 0.120 & 0.858 & 1.622 & 2.076 & -2.165 & -0.686 & -0.071 & 4.132 & 2.927 & 1.112 & 0.812 & 2.681 & 2.605 \\
\hline & 10 & 100 & 5 & ( & & 8 & 6.46 & 5025 & $6 r$ & -0.100 & -0.1 & 1 & & 2 & 2.266 & -1.4 & -1.2 & -0. & & & 39 & & 4 & 2.018 \\
\hline & 674 & & 2.745 & & & & & & & & & -0.124 & & & 2.218 & & -1.823 & -0.754 & & & 2.014 & 0.374 & 0.133 & 1.051 \\
\hline $3-2014$ & . & 1.750 & 2.838 & 0.361 & 0.742 & 1.144 & 7.166 & 6.181 & 4.522 & 0.040 & -0.011 & -0.174 & 0.9 & 1.146 & 2.247 & -0.939 & -0.701 & -0.799 & 5.2 & 4.271 & 2.474 & 0.347 & .782 & . \\
\hline 14 & 2 & 701 & 4 & 0.612 & $13 J$ & 1.661 & 1.40 & 6. & 956 & -1 & 0.00 & -0.170 & 0 & 1.000 & 2.145 & -0.334 & -0.942 & 81 & 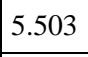 & 1 & 2.923 & 0.0 & 18 & 191 \\
\hline & 7 & 23 & 881 & 395 & 444 & 71 & 4.462 & 8 & 97 & 016 & 0.098 & 40 & 0.448 & 03 & 1.652 & 325 & 09 & 71 & 44 & 86 & 2 & 1.609 & 36 & 2.07 \\
\hline
\end{tabular}


Figure 1 compares the two change curves of the total factor productivity in China between 1995 and 2015 (with and without considering environmental regulation), the growth rate of total factor productivity declines in most years if taking environmental regulation into consideration. The total factor productivity that takes environmental regulation into consideration can reflect the performance of green economy growth and indicates that environmental regulation results in technical inefficiency during the development of China's economy, and therefore deters the growth rate of total factor productivity. This goes against the "the theory of Innovation Compensation" proposed by many scholars in recent years and conforms to the "the theory of Compliance Cost" proposed by scholars at early phase. It indicates that environmental regulation forces enterprises to occupy productive investment, and enterprises will suffer private cost increase to meet environmental requirements and will reduce the production efficiency. This will exert negative effects on China's economic development and deter the growth of total factor productivity in the long run (Alkin, 2016).

Figure 2 makes decomposition of the sources of growth of total factor productivity with environmental regulation considered. It can be figured out that technical efficiency contributes the most. The growth rate of cutting-edge technique progress is negative before 2004, but turns positive gradually after 2004. The change of scale efficiency exerts positive influence on the growth rate of total factor productivity, but the influence is not obvious. It is worth noting that the growth rate of allocation efficiency is negative in most times, and it is an important factor that restricts the growth of total factor productivity.

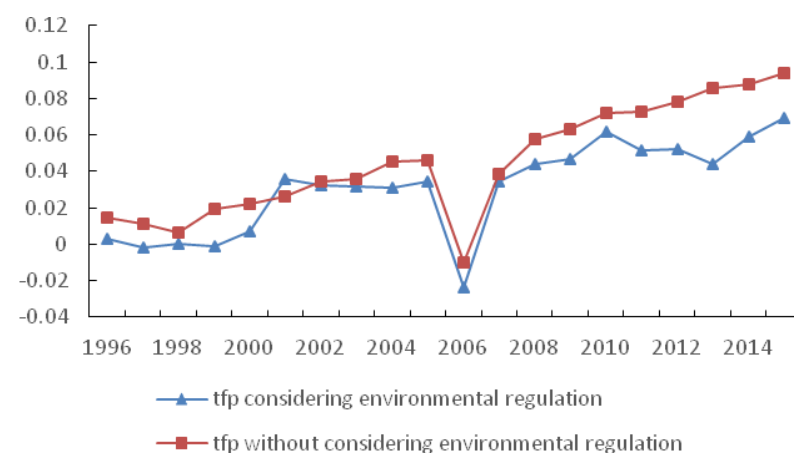

Figure 1. TPF growth in China with and without considering environmental regulation over 1995-2015(in \%)

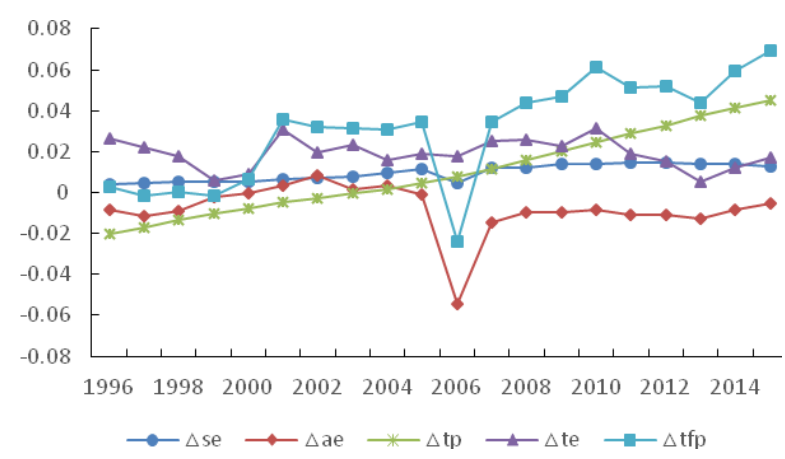

Figure 2. TFP growth and its decomposition in China considering environmental regulation over 1995-2015(in \%) 


\section{Conclusion}

In this paper, the authors constructs the translog stochastic frontier production function model, brings the index of correlation of environmental regulation into the equation of technical inefficiency to make maximum likelihood estimation, worked out the growth rate and compositions of total factor productivity in China as a whole and Eastern, Central and Western regions from 1995 to 2015, and makes a comparison analysis of the total factor productivity without considering the environmental regulation. The main conclusions are as follows:

(1) Total factor productivity slows down when taking environmental regulation into technical inefficiency. The investment of industrial pollution control and emission intensity of industrial $\mathrm{SO}_{2}$ all result in technical inefficiency, and are harmful to the improvement of total factor productivity. The influence of the number of environmental legislation published by local governments is not obvious. This indicates that there are still numerous things to be done to achieve China's win-win situation between environment and economy. Governments should carry out functional environmental regulations and manage the implementation of these regulations properly based on local resources and pollution status of local environment during the process of economic development. For enterprises that discharge pollutants out of their own benefits, government should fully arouse enterprises' enthusiasm and initiative of energy conservation and emission reduction to form an incentive and restraint mechanism of energy conservation and emission reduction.

(2) After taking environmental regulation into consideration, technical efficiency change becomes the main source of the growth of total factor productivity, technological progress slows down and the decline of growth of total factor productivity is closely related to the negative growth of allocation efficiency. The majority part of the eastern regions have been in the diseconomy of scale, so for these provinces, it is more important to improve the efficiency of resource utilization and the introduction and application of advanced technology to drive the progress of frontier technology rather than to expand the input and scale.

(3) The difference of total factor productivity growth rate in various regions of China has gradually narrowed in recent years, with the central and western regions even surpassing the eastern region, but it still shows obvious regional characteristics. After considering the environmental regulation, there exist differences in the reasons for the decrease of total factor productivity in various regions. Therefore, when formulating the environmental regulation, practical and feasible measures should be adopted through taking into account the differences in resources endowment, industrial structure and development stages of various regions.

Therefore, in the future, we should properly improve our environmental regulation system and adopt flexible forms of environmental regulation to ensure the positive impact of TFP on the environment.

\section{REFERENCES}

[1] Abija, F. A., Nwankwoala, H. O. (2018): Characterization of aquifers in parts of Abia State Southeastern Nigeria. - Earth Sciences Pakistan 2(1): 18-22.

[2] Aklin, M. (2016): Re-exploring the trade and environment nexus through the diffusion of pollution. - Environmental \& Resource Economics 64(4): 663-682. 
[3] Anan, H. S. (2019): Contribution to the paleontology, stratigraphy and paleobiogeography of some diagnostic Pakistanian Palaeogene foraminifer in the Middle East. - Earth Sciences Pakistan 3(1): 23-28.

[4] Baharuddin, D., Samsudin, M. D. M. (2018): Effect of $\mathrm{pH}$ and moisture content on current density of impressed current cathodic protection: response surface methodology study. - Environment \& Ecosystem Science, 2(2): 15-19.

[5] Barla, P., Perelman, S. (2005): Sulphur emissions and productivity growth in industrialised countries. - Annals of Public \& Cooperative Economics 76(2): 275-300.

[6] Brolund, J., Lundmark, R. (2017): Effect of environmental regulation stringency on the pulp and paper industry. - Sustainability 9(12): 2323.

[7] Cai, W. G., Zhou, X. L. (2017): Dual effect of Chinese environmental regulation on green total factor productivity. - Economist 9: 27-35.

[8] Chen, L. (2017): Dual nature of environmental regulation: restraining or promoting technological progress - evidence from Wuhan City circle. - Science \& Technology Progress and Policy 34(12): 43-48.

[9] Chen, Y., Zhang, J. (2016): Carbon emission, green total factor productivity and economic growth. - The Journal of Quantitative \& Technical Economics 8: 47-63.

[10] Cherkashin, I., Demidova, S., Kee, H. L. (2015): Firm heterogeneity and costly trade: a new estimation strategy and policy experiments. - Journal of International Economics 96(1): 18-36.

[11] Cole, M. A., Elliott, R. J. R., Shanshan, W. U. (2008): Industrial activity and the environment in China: an industry-level analysis. - China Economic Review 19(3): 393 408.

[12] Gautam, A., Batra, R., Singh, N. (2019): A study on use of rice husk ash in concrete. Engineering Heritage Journal 1(1): 01-04.

[13] González, L. C. (2016): Efecto de la cachaza más roca fosfatada enriquecida con microorganismos sobre la disponibilidad, absorción de $\mathrm{P}$ y el crecimiento del maíz en dos tipos de suelo. - Revista de la Facultad de Agronomia de la Universidad del Zulia 33(1).

[14] Granderson, G., Prior, D. (2013): Environmental externalities and regulation constrained cost productivity growth in the US electric utility industry. - Journal of Productivity Analysis 39(3): 243-257.

[15] Guo, D., Bose, S., Alnes, K. (2015): Employment implications of stricter pollution regulation in China: theories and lessons from the USA. - Environment Development \& Sustainability 19(2): 549-569.

[16] Hajikhani, S. (2017): 8. The effect of planting date and applications herbicide on the population, weed dry matter and grain yield of chintzy beans. - Revista de la Facultad de Agronomia de la Universidad del Zulia 34(3).

[17] Huang, N, Jiang, Y. J., Liu, R. C., Li, B. O., Zhang, Z. Y. (2017): A predictive model of permeability for fractal-based rough rock fractures during shear. - Fractals 25(5). https://doi.org/10.1142/S0218348X17500517.

[18] Jamali, F. (2016): 5. Effects of planting distance and weeding regime on green bean (Phaseolus vulgaris L.) growth and yield. - Revista de la Facultad de Agronomia de la Universidad del Zulia 33(3).

[19] Klemetsen, M. E., Bye, B., Raknerud, A. (2016): Can direct regulations spur innovations in environmental technologies? A study on firm-level patenting. - Scandinavian Journal of Economics 120(2): 338-371.

[20] Kumar, R., Kumar, V. (2018): A review of phylogeography: biotic and abiotic factors. Geology, Ecology, and Landscapes 2(4): 268-274.

[21] Kumbhakar, S. C., Lovell, C. A. K. (2000): Stochastic frontier analysis. - Cambridge University Press, Cambridge.

[22] Li, X. J., Du, W., Wang, X. F. (2017): Environmental tax system and green development: based on the perspective of technological progress. - Modern Economic Science 39(4): 117-123. 
[23] Liu, H. W., Zheng, S. L., Zuo, W. T. (2016): The influence mechanism of environmental regulation on TFP of enterprises. - Science Research Management 37(5): 33-41.

[24] Lv, K. J., Cheng, Y., Fan, B. J. (2017): The relations study on environmental regulation and green total factor productivity of China's manufacturing industry. - Ecological Economy 33(4): 49-52.

[25] Mut, Z. (2018): 3. Evaluation of hay yield and quality traits of oat genotypes grown at different locations. - Revista de la Facultad de Agronomia de la Universidad del Zulia $35(2)$.

[26] Naso, P. (2017): The porter hypothesis goes to China: spatial development. Environmental regulation and productivity. - CIES Research Paper Series 53-2017, Centre for International Environmental Studies, The Graduate Institute.

[27] Onwuka, O. S., Ezugwu, C. K., Ifediegwu, S. I. (2019): Assessment of the impact of onsite sanitary sewage system and agricultural wastes on groundwater quality in Ikem and its environs, south-eastern Nigeria. - Geology, Ecology, and Landscapes 3(1): 65-81.

[28] Pascual-Córdova, G. (2018): 1. Indicadores de calidad del suelo en el agroecosistema caña de azúcar (Saccharum spp.). - Revista de la Facultad de Agronomia de la Universidad del Zulia 35(1).

[29] Perozo, J. V. (2016): 6. Germinación de embriones somáticos de Psidium guajava L. en envases de cultivo con ventilación forzada. - Revista de la Facultad de Agronomia de la Universidad del Zulia 33(2).

[30] Qu, X. E. (2015): Industry characteristics, environmental regulation and productivity growth-Based on the test of the "Porter Hypothesis". - Soft Science 2015-02.

[31] Qu, X. E., Xi, Y. (2012): Total factor productivity in China under the dual regulation of the resourses and the environment - Empirical analysis based on the data of 1996-2009. Journal of Business Economics 1(5): 89-96.

[32] Ravetti, C., Theoduloz, T., Valacchi, G. (2016): Energy, trade and innovation: the tragedy of the locals. - CIES Research Paper 41-2016. Centre for International Environmental Studies, The Graduate Institute.

[33] Shan, H. J. (2008): Reestimating the capital stock of China: 1952 2006. - The Journal of Quantitative \& Technical Economics 10: 17-31.

[34] Solow, R. M. (1957): Technical change and the aggregate production function. - Review of Economics \& Statistics 39(3): 554-562.

[35] Sufiyan, I., Zakariya, R., Yacoob, R., Idris, M. S., Idris, N. M. (2018): SWAT subbasins parameters and flood risk simulations using $3 \mathrm{~d}$ in Terengganu watershed. - Earth Sciences Malaysia 2(2): 10-15.

[36] Thanh, L. D., Do, P. V. (2018): Streaming current induced by fluid flow in porous media. - Earth Sciences Malaysia 2(1): 22-28.

[37] Tian, Y. H., He, S. B., Hu, S. Q. (2011): Re-estimation of China's regional total factor productivity growth under environment regulation: 1998-2008. - China Industrial Economics 1: 47-57.

[38] Wang, H. J., Schmidt, P. (2002): One-step and two-step estimation of the effects of exogenous variables on technical efficiency levels. - Journal of Productivity Analysis 18(2): 129-144.

[39] Wang, J., Sheng, P. F. (2015): Does environmental management reduce Chinese industrial total-factor productivity: a study based on modified directional distance function. - Industrial Economics Research 5: 31-39.

[40] Wang, W., Qi, L. Q. (2017): Volatility and heterogeneity of total factor productivity growth in China's equipment manufacturing industry. - The Journal of Quantitative \& Technical Economics 10: 111-127.

[41] Wang, Z. G., Gong, L. T., Chen, Y. Y. (2006): China's regional differences in technical efficiency and the decomposition of total factor productivity growth (1978-2003). Social Sciences in China 2: 55-66. 


$$
-8434-
$$

[42] Xiao, X. J., Yang, G. (2017): China energy situation analysis in 2016 and prospects in. Energy of China 39(3): 5-12.

[43] Xiong, Y. Q., Han, M. A., Romanovski, V. G. (2017): The maximal number of limit cycles in perturbations of piecewise linear Hamitonian systems with two saddles. International Journal of Bifurcation and Chaos 27(8).

[44] $\mathrm{Xu}, \mathrm{D}$. (2018): Research on brand construction and development of agricultural products in Guizhou. - Engineering Heritage Journal 2(2): 19-24.

[45] Yu, M. (2019): Impact of environmental regulation on green innovation practice of food enterprises: regulating effect of environmental awareness of different executives. Revista de la Facultad de Agronomia de la Universidad del Zulia 36(1).

[46] Yuan, Q., Chen, C. S., Yang, H. W. (2017): Existence of positive solutions for a Schrödinger-Poisson system with bounded potential and weighted functions in R3. Boundary Value Problems (2017): 151.

[47] Zárate-Marco, A., Vallés-Giménez, J. (2015): Environmental tax and productivity in a decentralized context: new findings on the Porter hypothesis. - European Journal of Law \& Economics 40(2): 313-339.

[48] Zulkapli, M. F., Rashid, N. M., Sokri, M. N. M., Nasri, N. (2018): Study on optical properties of graphene-Tio2 nanocomposite as photoanodes layer in dye sensitized solar cell (DSSC). - Environment \& Ecosystem Science 2(2): 39-41. 